$\underline{\text { Article }}$

\title{
Models of the Electroreduction of Passive Layers on Cobalt
}

\author{
C.A. Gervasi ${ }^{*}$ \\ Instituto de Investigaciones Fisicoquímicas Teóricas y Aplicadas (INIFTA), Facultad \\ de Ciencias Exactas, Universidad Nacional de La Plata, Sucursal 4, C.C. 16,
}

1900 La Plata, Argentina

Received: June 30, 1996; November 18, 1996

\begin{abstract}
Técnicas de transientes de corrente potenciostáticos foram empregadas no estudo de processos de eletroredução de camadas superficiais formadas no cobalto policristalino em soluções contendo íons carbonato-bicarbonato. As análises dinâmicas do sistema, realizadas através de procedimentos de investigação paramétrica e de rotinas de ajuste não-lineares, demonstraram que os dados obtidos sob numa grande variedade de condições experimentais podem ser interpretados considerando a participação de várias espécies superficiais contendo $\mathrm{Co}(\mathrm{II}) / \mathrm{Co}(\mathrm{III})$. A influência do tempo de anodização no potencial de formação do óxido pode ser discutida na base dos modelos de eletroredução aqui propostos.

Potentiostatic current transient techniques were employed to study the electroreduction process of surface layers formed on polycrystalline cobalt in carbonate-bicarbonate ion-containing solutions. The dynamic system analysis performed using parametric identification procedures and non-linear fit routines demonstrated that data obtained under a wide variety of experimental conditions may be interpreted by taking into account the participation of various $\mathrm{Co}(\mathrm{II}) / \mathrm{Co}$ (III)-containing surface species. The influence of the anodizing time at the potential of oxide film formation may be discussed on the basis of the proposed electroreduction models.
\end{abstract}

Keywords: Cobalt oxides, electroreduction, potential steps, kinetic models

\section{Introduction}

Anodic oxide films formed on cobalt in alkaline solutions have been investigated in the past in order to derive the most likely structure of the oxidation products, as well as their properties. Electrochemical and ellipsometric studies were used to propose the overall mechanisms for the electro-oxidation reactions ${ }^{1-2}$. The passive films that are formed in the potential range of the secondary passivity present a bilayer structure and aging processes may be produced by proper polarization programs ${ }^{3}$. By contrast, the electroreduction of these surface layers has received comparatively less attention. Moreover, it should be expected that the corresponding reaction mechanisms are consistent with the previously advanced electro-oxidation pathways. The analysis of electroreduction using potential-step techniques may yield significant information concerning not only the kinetics of the reaction of this process, but also the nature of the passive film and the kinetics of its growth and dissolution ${ }^{4,5}$.

In this article, a study of the electroreduction of cobalt passive films formed through potential controlled anodization in carbonate-bicarbonate buffers is presented. Furthermore, the potentialities of the electroreduction potential-steps technique in the study of passive state properties will be disclosed.

\section{Experimental}

The experimental setup has been described in previous publications $\mathrm{s}^{4,6}$. "Specpure" cobalt in the form of both static and rotating disks (Johnson Matthey Chemical, $0.30 \mathrm{~cm}^{2}$ apparent area), embedded in PTFE holders was used for the working electrodes. Potentials were measured against a saturated calomel electrode (SCE) $(0.242 \mathrm{~V}$ in the NHE scale), but in the text they are referred to the NHE. The electrolyte solution consisted of $x \mathrm{M} \mathrm{KHCO}_{3}$ y $\mathrm{M} \mathrm{K}_{2} \mathrm{CO}_{3}$ 
$(0.0075 \leq \mathrm{x} \leq 0.75 ; 0.0005 \leq \mathrm{y} \leq 1.5)$ covering the 8.4-11.6 $\mathrm{pH}$ range. The solutions were prepared from analytical grade (p.a. Merck) reagents and triply-distilled water, previously boiled under inert atmosphere to remove $\mathrm{CO}_{2}$. The working electrode surface was finely polished with $\gamma$-alumina $(1.0$ and $0.3 \mu \mathrm{m})$, rinsed in triply-distilled water, and finally cathodically polarized for $\tau_{0}=3 \mathrm{~min}$ at potentials sufficiently negative to produce a net hydrogen evolution.

Experiments were made under purified $\mathrm{N}_{2}$ gas saturation at $25^{\circ} \mathrm{C}$ by employing the following perturbing potential programs: $i$ ) single (STPS) triangular potential scans between preset cathodic $\left(\mathrm{E}_{\mathrm{s}, \mathrm{c}}\right)$ and anodic $\left(\mathrm{E}_{\mathrm{s}, \mathrm{a}}\right)$ switching potentials at a scan rate of $\mathrm{v}=0.025 \mathrm{~V} \mathrm{~s}^{-1}$; ii) combined potential scans and potentiostatic steps, usually two potential steps, covering different potential regions. The first potential step $\left(E_{i}\right)$ was applied for a certain time $\tau$ to modify the anodically formed layer in order to change the total amount of anodic surface products and to produce aging effects which may vary the composition of the anodic layer constituents. Most of these current transient experiments were performed by setting $E_{i}=E_{s, a}$. The second potential step $\left(E_{f}\right)$ was fixed sufficiently negative to electroreduce the anodic layer either partially or completely, and the corresponding current transients were systematically recorded.

\section{Results and Discussion}

It has already been established that the region of primary passivity of cobalt electrodes in alkaline media covers the 0.4-0.6 $\mathrm{V}$ range for potentials referred to the hydrogen electrode in the same electrolyte $\left(\mathbf{U}_{\mathrm{Hss}}\right)^{7}$. $\mathrm{Co}(\mathrm{II})$ oxide or the respective hydroxide is the stable phase in this potential range. Beyond that, i.e. in the region of secondary passivity, a spinel phase becomes stable and the film consists of an inner layer of $\mathrm{CoO}$ and an outer layer of $\mathrm{Co}_{3} \mathrm{O}_{4}{ }^{8}$. As such, setting $\mathrm{E}_{\mathrm{s}, \mathrm{a}}=0.14 \mathrm{~V}$ ( $v s$. NHE) renders a film corresponding to the secondary passivity, i.e. $\mathrm{E}_{\mathrm{s}, \mathrm{a}} \geq 0.6 \mathrm{~V}$ ( $v$ s. $\mathrm{U}_{\mathrm{Hss}}$, in the $\mathrm{pH}$ range studied in this work.

The voltammogram of cobalt in $0.75 \mathrm{M} \mathrm{KHCO}_{3}+0.05$ $\mathrm{M} \mathrm{K}_{2} \mathrm{CO}_{3}$ solution, at $\mathrm{pH} 8.9$, and run at $\mathrm{v}=0.025 \mathrm{~V} \mathrm{~s}^{-1}$ shows (Fig. 1) one main anodic peak at c.a. $-0.17 \mathrm{~V}$ (peak II) and two satellite humps, one at c.a. $-0.33 \mathrm{~V}$ (peak I) and the other at $0.07 \mathrm{~V}$ (peak II*), which precedes the onset of the secondary passive current region. The reverse scan presents a reactivation of the electro-oxidation process followed by a limiting current region prior to a cathodic peak at $-0.63 \mathrm{~V}$ and a cathodic current at potentials lower than $-0.75 \mathrm{~V}$, largely due to the hydrogen evolution reaction. The presentation of Fig. 1 is simply intended to show the potential regions where the main electrochemical reactions take place. A detailed description may be found in Ref. 2.

The electroreduction of cobalt oxide layers was investigated through the potentiostatic current transient method. In the case of nucleation and egrowth-controlled processes,

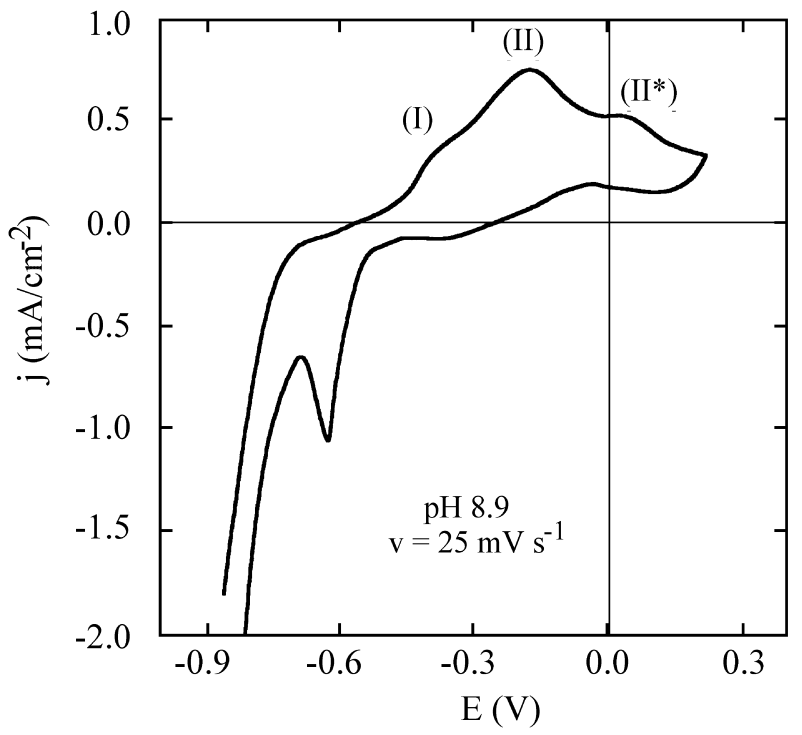

Figure 1. Voltammograms run at $\mathrm{v}=0.025 \mathrm{~V} \mathrm{~s}^{-1}$ between $\mathrm{E}_{\mathrm{s}, \mathrm{c}}=-0.86$ $\mathrm{V}$ and $\mathrm{E}_{\mathrm{s}, \mathrm{a}}=0.22 \mathrm{~V}$ in $0.75 \mathrm{M} \mathrm{KHCO}_{3}+0.05 \mathrm{M} \mathrm{K}_{2} \mathrm{CO}_{3}$ solution, $\mathrm{pH}$

experimental studies using this method are usually preferred, because then the electrochemical rate parameters are constant for $\mathrm{t}>0$. In a previous paper ${ }^{6}$, the systematic analysis of potential steps for the electroreduction reaction were described for the same systems considered in this work. It was concluded that for a fixed value of $\tau=30 \mathrm{~s}$, the current transients can be well described according to the following theoretical model:

$$
j(t)=\frac{P_{3}}{t 1 / 2}+P_{1}\left[1-\exp \left(-P_{2} t_{1}^{3}\right)\right.
$$

where

$$
\begin{aligned}
& \mathrm{t}_{\mathrm{i}}=\mathrm{t}-\mathrm{t}_{\text {lag }}=\mathrm{t}-\mathrm{P}_{4} \\
& \mathrm{P}_{1}=\mathrm{zFk_{1 }} \\
& \mathrm{P}_{2}=\frac{\pi \mathrm{M}^{2} \mathrm{k}_{2}^{2} \mathrm{~A}}{3 \rho^{2}}
\end{aligned}
$$

and

$$
\mathrm{P}_{3}=\frac{\mathrm{zF} \mathrm{D}^{1 / 2} \Delta \mathrm{c}}{\pi^{1 / 2}}
$$

$\mathrm{k}_{1}\left(\mathrm{~mol} \mathrm{~cm} \mathrm{~cm}^{-2}\right)$ and $\mathrm{k}_{2}\left(\mathrm{~mol} \mathrm{~cm} \mathrm{~s}^{-2} \mathrm{~s}^{-1}\right)$ stand for the new phase growth rate constants respectively perpendicular and parallel, to the electrode surface; $\mathrm{M}\left(\mathrm{g} \mathrm{mol}^{-1}\right)$ and $\rho\left(\mathrm{g} \mathrm{cm}^{-3}\right)$ are the molecular weight and specific weight of the growth phase, respectively; A (nuclei $\mathrm{cm}^{-2} \mathrm{~s}^{-1}$ ) is the nucleation rate constant; $\mathrm{D}\left(\mathrm{cm}^{-2} \mathrm{~s}^{-1}\right)$ and $\Delta \mathrm{c}\left(\mathrm{mol} \mathrm{cm}{ }^{-3}\right)$ are respectively, the diffusion coefficient and the concentration gradient of the diffusing species across the Nernst diffusion layer. This global model involves the sum of two terms, a simple diffusion law and a relationship according to pro- 
gressive nucleation and three-dimensional (3D) growth of nuclei under charge transfer control ${ }^{9}$. The model also includes the appearance of an induction time $\left(\mathrm{P}_{4}\right)$ for the formation of 3D nuclei. Figure 2 shows experimental current transients obtained in $0.075 \mathrm{M} \mathrm{KHCO}_{3}+0.005 \mathrm{M} \mathrm{K}_{2} \mathrm{CO}_{3}$ solution, at $\mathrm{pH} 8.9$, with a potential step between $\mathrm{E}_{\mathrm{i}}=0.14$ $\mathrm{V}$ and $\mathrm{E}_{\mathrm{f}}=-0.74 \mathrm{~V}$, and at times $\tau=8 \mathrm{~s}$ and $30 \mathrm{~s}$. A good agreement can be observed between the experimental values and the theoretical curves calculated with Eq. 1. However, when $E_{\mathrm{f}}$ is set $\geq-0.57 \mathrm{~V}$, the experimental current transients lack the maximum typical for a nucleation and growth controlled process. Figure 3 depicts an experimental current transient recorded at $\mathrm{E}_{\mathrm{f}}=-0.57 \mathrm{~V}$ in $0.75 \mathrm{M}$ $\mathrm{KHCO}_{3}+0.05 \mathrm{M} \mathrm{K}_{2} \mathrm{CO}_{3}$ solution, at $\mathrm{pH} 8.9$, with $\tau=3 \mathrm{~s}$, together with the corresponding theoretical curve derived

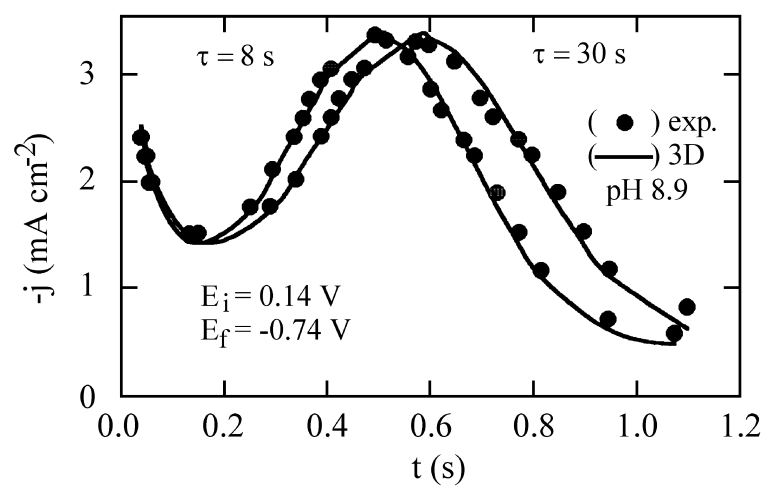

Figure 2. Experimental current transients $[\bullet]$ recorded at $\mathrm{E}_{\mathrm{f}}=-0.74 \mathrm{~V}$ in $0.075 \mathrm{M} \mathrm{KHCO}_{3}+0.005 \mathrm{M} \mathrm{K}_{2} \mathrm{CO}_{3}$ solution, at $\mathrm{pH} 8.9$, at different $\tau \mathrm{s}$. The theoretical curves were derived from the fitting of these data according to Eq. 1 [-].

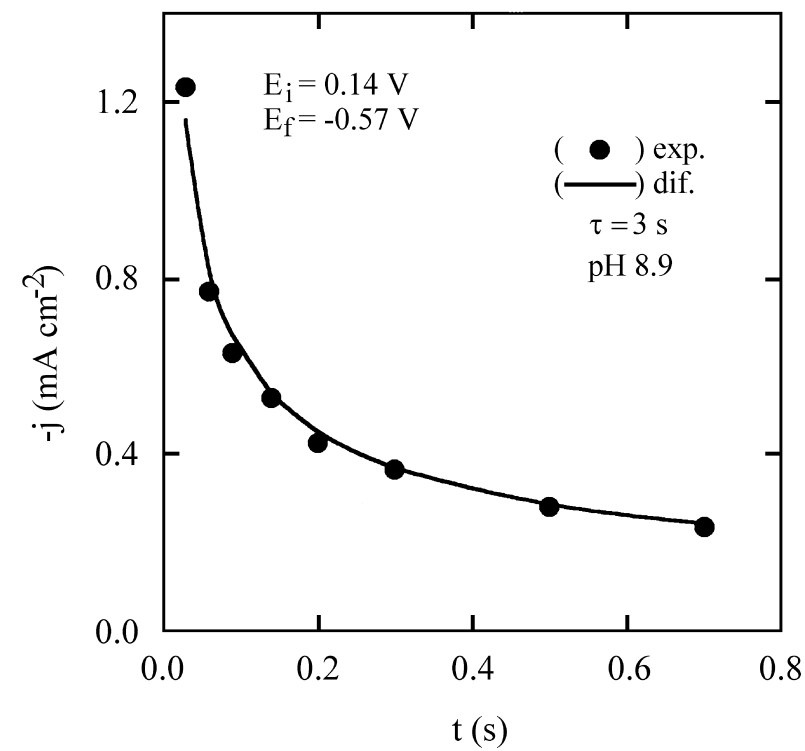

Figure 3. Experimental current transient $[\bullet]$ recorded at $\mathrm{E}_{\mathrm{f}}=-0.57 \mathrm{~V}$ in $0.75 \mathrm{M} \mathrm{KHCO}_{3}+0.05 \mathrm{M} \mathrm{K}_{2} \mathrm{CO}_{3}$ solution, at $\mathrm{pH} 8.9$, with $\tau=3 \mathrm{~s}$. The theoretical curve derived from the fitting of these data according to the diffusion term of Eq. 1 [-]. through fitting to the initial diffusion term in Eq. 1. This type of kinetic law at first sight suggests that under these working conditions, the electroreduction reaction, corresponds to a process controlled solely by diffusion.

The proposed theoretical model in Eq. 1 also fails to properly describe the experimental transients obtained at longer times $\tau$. Thus, Fig. 4 shows two current transients recorded under the experimental conditions described in Fig. 2, but with $\tau=90 \mathrm{~s}$ (Fig. 4 a) and $\tau=180 \mathrm{~s}$ (Fig. 4 b). The experimental results at a longer $\tau$ can be satisfactorily described according to the following relationship:
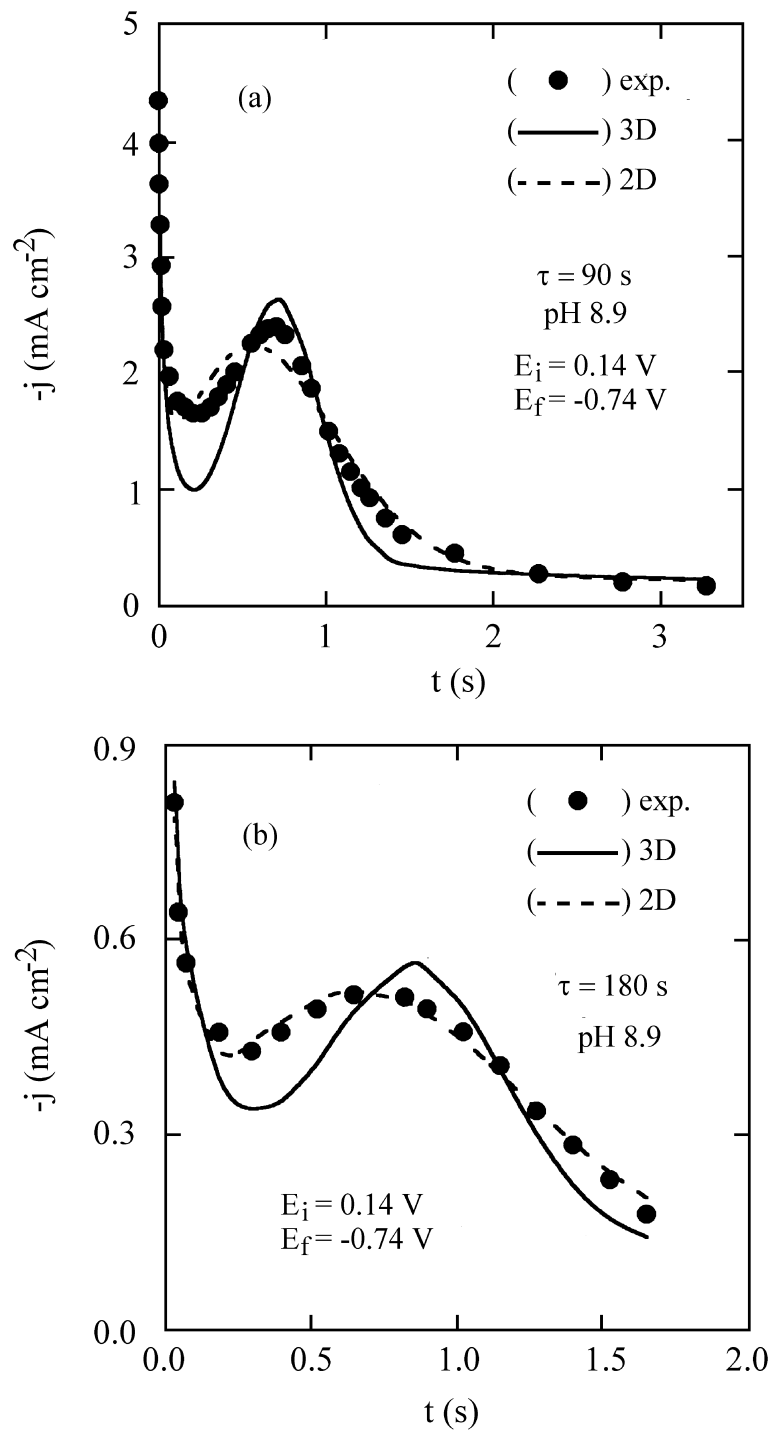

Figure 4. Experimental current transients $[\bullet]$ recorded at $E_{f}=-0.74 \mathrm{~V}$ in $0.075 \mathrm{M} \mathrm{KHCO}_{3}+0.005 \mathrm{M} \mathrm{K}_{2} \mathrm{CO}_{3}$ solution, at $\mathrm{pH} 8.9$, for (a) $\tau=$ $90 \mathrm{~s}$ and (b) $\tau=180 \mathrm{~s}$. The fitting of these data was according to Eq. 1 [-] and Eq. 6 [- - ]. 


$$
\mathrm{j}(t)=\frac{\mathrm{P}_{3}}{\mathrm{t}^{1 / 2}}+\mathrm{P}_{5} \mathrm{t}_{\mathrm{i}} \exp \left(-\mathrm{P}_{6} \mathrm{t}_{\mathrm{i}}^{2}\right)
$$

where

$$
\begin{aligned}
& \mathrm{P}_{5}=\frac{2 \mathrm{zF} \pi \mathrm{h} \mathrm{Mk}_{2}^{2} \mathrm{~N}_{0}}{\rho} \\
& \mathrm{P}_{6}=\frac{\pi \mathrm{M}^{2} \mathrm{k}_{2}^{2} \mathrm{~N}_{0}}{\rho}
\end{aligned}
$$

$h$ is the height of the growth layer when $N_{0}$ nuclei are instantaneously formed, and the rest of the symbols have already been defined. In this case, the initial diffusion term remains unchanged, while the second term corresponds to an instantaneous nucleation and 2D growth process under charge transfer control ${ }^{10}$. Figure 4 contains best-fit curves according to Eqs. 1 and 6. A comparison of these results makes it clear that a transition from a $3 \mathrm{D}$ to a $2 \mathrm{D}$ growth model can be mainly associated with longer aging times $\tau$.

Experimental current transients recorded at different $\tau \mathrm{s}$ in a $0.75 \mathrm{M} \mathrm{KHCO}_{3}+1.5 \mathrm{M} \mathrm{K}_{2} \mathrm{CO}_{3}$ solution, at $\mathrm{pH} 10.5$, are depicted in Fig. 5, together with the corresponding theoretical curves derived through fitting to Eq. 6. Even for very short times $\tau$ the nucleation and growth model corresponds to a $2 \mathrm{D}$ process. The values of the parameters, as derived from the fitting procedure, are assembled in Table 1, which also includes the height of the growth phase $h$ and the electroreduction charge density q comprised in the nucleation and 2D growth processes. These values were calculated as follows:

$$
\begin{aligned}
& \mathrm{h}=\frac{\frac{\mathrm{P}_{5}}{\mathrm{P}_{6}} \mathrm{M}}{2 \mathrm{zF} \rho} \\
& \mathrm{q}=\int_{0}^{\infty} \mathrm{P}_{5} \mathrm{t} \exp \left(-\mathrm{P}_{6} \mathrm{t}^{2}\right) \mathrm{dt}=\frac{\mathrm{P}_{5}}{2 \mathrm{P}_{6}}
\end{aligned}
$$

The values of h calculated with Eq. 9 decrease with increasing times $\tau$, and are in good agreement with the thickness of the primary passive layer of $\mathrm{CoO}$ electroformed in other electrolytes at comparable $\mathrm{pH}$ values ${ }^{8}$.

An enhanced chemical dissolution of the inner $\mathrm{CoO}$ layer is to be expected in solutions with increased concentrations of carbonate and bicarbonate ions, like the electrolyte used in the experiments in Fig. $5^{2}$. The earlier exhaustion of electroactive species in the oxide film in the perpendicular direction imposes a physical limit for further vertical 3D growth and determines the observed $2 \mathrm{D}$ behavior. This is a consequence of a thinning of the film by its enhanced dissolution after longer times in contact with the electrolyte.

The reactions taking place during the electroreduction of passive cobalt electrodes formed in the secondary passivity region in carbonate-bicarbonate solutions can be put as follows:

$$
\begin{aligned}
& \mathrm{Co}_{3} \mathrm{O}_{4}+4 \mathrm{H}_{2} \mathrm{O}+2 \mathrm{e}^{-} \longrightarrow 3 \mathrm{Co}^{2+}+8 \mathrm{OH}^{-} \\
& \mathrm{Co}^{2+}+2 \mathrm{HCO}_{3}{ }^{-} \longrightarrow \mathrm{Co}\left(\mathrm{CO}_{3}\right)_{2}{ }^{2-}+2 \mathrm{H}^{+} \\
& \mathrm{CoO}+2 \mathrm{H}^{+}+2 \mathrm{e}^{-} \longrightarrow \mathrm{Co}+\mathrm{H}_{2} \mathrm{O}
\end{aligned}
$$

Reaction 11 corresponds to an electroreductive dissolution of the outer $\mathrm{Co}_{3} \mathrm{O}_{4}$ layer with the formation of soluble $\mathrm{Co}$ (II) species, rather than an oxide layer with lower valency. This reaction may explain the electroreduction charge in the transients associated with a diffusion controlled process and the limiting current detected in the voltammogram of Fig. 1. Moreover, Reaction 11 has previously been proposed to explain the electroreduction of cobalt oxide layers formed in electrolytes containing borate ions by means of measuring techniques different from those described here ${ }^{1}$.

Reaction 12 takes into account the formation of a complex ion of $\mathrm{Co}$ (II) which has been shown to be the stable form in carbonate-bicarbonate containing solutions ${ }^{12}$. Although the diffusion current in the transients was related, in a different fashion, to a reaction involving the complex ion

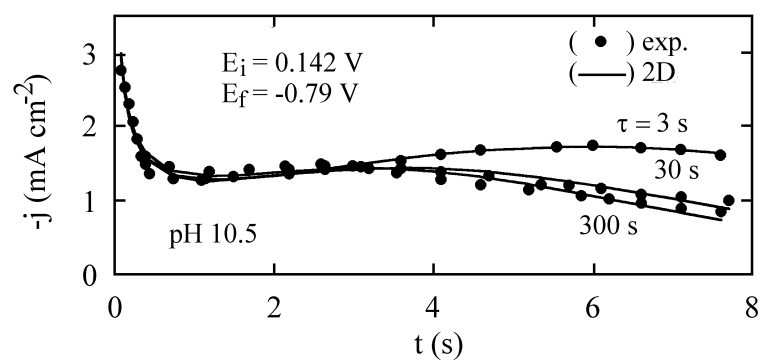

Figure 5. Experimental current transients $[\bullet]$ recorded at $\mathrm{E}_{\mathrm{f}}=-0.79 \mathrm{~V}$ in $0.75 \mathrm{M} \mathrm{KHCO}_{3}+1.5 \mathrm{M} \mathrm{K}_{2} \mathrm{CO}_{3}$ solution, at $\mathrm{pH} 8.9$, at different $\tau$. The theoretical curves were derived from the fitting of these data ac-

Table 1. Parameters used for fitting the electroreduction current decay data in $0.75 \mathrm{M} \mathrm{KHCO}_{3}+1.5 \mathrm{M} \mathrm{K}_{2} \mathrm{CO}_{3}$, at pH 10.5 , according to Eq. 6 for $\mathrm{P}_{4}$ , 0; the height of the growth phase h calculated with Eq. 9 and the electroreduction charge density q, calculated with Eq. 10.

\begin{tabular}{lccccc}
\hline$\tau / \mathrm{s}$ & $\mathrm{P}_{3} / \mathrm{mAcm}^{-2} \mathrm{~s}^{1 / 2}$ & $\mathrm{P}_{5} / \mathrm{mAcm}^{-2} \mathrm{~s}^{-1}$ & $\mathrm{P}_{6} / \mathrm{s}^{-2}$ & $\mathrm{q} / \mathrm{mCcm}^{-2}$ & $\mathrm{~h} / \mathrm{nm}^{2}$ \\
\hline 3 & 0.925 & 0.350 & 0.0126 & 13.9 & 4.77 \\
30 & 0.921 & 0.382 & 0.0289 & 6.61 & 2.27 \\
300 & 0.943 & 0.412 & 0.0370 & 5.57 & 1.91 \\
\hline
\end{tabular}


$\mathrm{Co}\left(\mathrm{CO}_{3}\right)_{2}{ }^{2-} \quad{ }^{6}$, no clear explanation was given for the $\mathrm{Co}(\mathrm{III}) \rightarrow \mathrm{Co}(\mathrm{II})$ transformation, which should be detected in the transients during the electroreduction of $\mathrm{Co}_{3} \mathrm{O}_{4}$ films.

As the potential applied to the electrode enters the potential window of the voltammetric cathodic peak, the reduction of the inner $\mathrm{CoO}$ to yield an electroreduced cobalt layer also takes place (Reaction 13). Reactions 11 and 13 probably involve multiple steps.

\section{Conclusions}

The proposed electroreduction pathway of cobalt oxides formed in the potential range of the secondary passivity in carbonate-bicarbonate buffers is consistent with the previously proposed structure of the passive films. As such, the mechanisms presented describe the electroreduction $\mathrm{ki}$ netics of both the outer $\mathrm{Co}_{3} \mathrm{O}_{4}$ layer and the inner $\mathrm{CoO}$ layer. The transition of the growth mechanism for the new phase from a $3 \mathrm{D}$ to a $2 \mathrm{D}$ process may be related to the time of potentiostatic aging $\tau$. The height of the growth phase $h$ can be correlated to the thickness of the anodic film, as previously measured using other techniques. The electroreduction potential step technique applied to anodic films has the ability not only to allow discrimination among different kinetic mechanisms, but also to provide information about the nature of these films.

\section{Acknowledgments}

